\title{
Effect of the electromagnetic environment in pipes in Yakutia
}

\author{
Vladimir I. Kozlov ${ }^{1,2, *}$, Larisa M. Abzaletdinova ${ }^{1}$, Lena D. Tarabukina ${ }^{1,2}$, Alexey \\ A. Korsakov ${ }^{1}$ and Yuri M. Grigoryev ${ }^{2}$ \\ ${ }^{1}$ Yu.G. Shafer Institute of Cosmophysical Research and Aeronomy SB RAS, 677000, Yakutsk, Russia \\ ${ }^{2}$ M.K. Ammosov North-Eastern Federal University, 677000, Yakutsk, Russia
}

\begin{abstract}
The results of measurements of telluric currents flowing through pipelines laid in the cryolithozone in Yakutia are presented during geomagnetic storms and lightning discharges occurring in the $10 \mathrm{~km}$ zone around the pipeline. The currents reach tens of amperes. Construction of a lightning density distribution map. The effect of a direct current flowing in a $150 \mathrm{~m}$ long pipeline with a diameter of $110 \mathrm{~mm}$ laid in permafrost on the change in the pipe-to-ground potential is measured. Based on the analysis of variations in the horizontal component of the magnetic activity in the current 24th cycle of solar activity, it is established that the frequency of occurrence of a certain level of the rate of change in geomagnetic activity can be expressed by a power law with an order of magnitude of about two at low values. The exponent decreases to unity as the geomagnetic activity increases. The probability of occurrence of time intervals with given threshold values of the rate of change of geomagnetic activity is determined.
\end{abstract}

\section{Introduction}

Geomagnetic field fluctuations and charged (thunderstorm) clouds create electric fields and, accordingly, currents in pipelines, called geomagnetically induced currents (GIT). Pipelines in Yakutia, for example, the pipeline Eastern Siberia-Pacific Ocean (ESPO), lay at a depth of $2 \mathrm{~m}$. In the transitional sections with different conductivity, there is a difference in electrical potentials between the pipeline and the earth, and electrochemical corrosion increases. The entry point of wandering currents will serve as a cathode, and the point of flow of currents will serve as an anode. Local corrosion of underground pipelines often manifests itself in the form of ulcers penetrating deep into the metal. Studies on the determination of GIT give values up to tens of amperes [1] and hundreds [2]. The induced current in the main objects can cause significant fluctuations in the potentials of the pipeline-ground (PPG). Changes in PPG can reach up to $1 \mathrm{~V}$ [3]. Because of the change in the potential "pipeline-ground" associated with telluric currents, the following problems arise. Positive values of PPG lead to corrosion. Fluctuations of PPG more than $0.85 \mathrm{~V}$

\footnotetext{
e-mail: vkozlov@ikfia.ysn.ru
} 
relative to the natural potential of the metal-ground $(-0.66 \mathrm{~V})$ can lead to increased corrosion, even taking into account the potential of protection $0.25 \mathrm{~V}$. Fluctuations of PPG up to $1.2 \mathrm{~V}$ can cause the production of hydrogen at the boundary between the metal and the coating, which will lead to a violation of the bond between the coating and the metal. Possible damage to electronic equipment connected to the pipeline [4].

\section{Methods of investigation}

An experimental study of the influence of the magnitude of the direct current flowing through the pipeline on the change in the potential difference between the pipeline and the ground was carried out on a part of the buried pipeline with the following parameters: length $150 \mathrm{~m}$, diameter $110 \mathrm{~mm}$, thickness $11 \mathrm{~mm}$. This section of the gas pipeline between Yakutsk and Tabaga crosses the bulk gravel road, creating a heterogeneity in the ground around the pipeline. It was obtained (Fig. 1) that the potential difference "pipeline-ground" ( $\Delta \mathrm{Up}$-gr) depending on the current in the pipeline (Ip) is expressed as $\Delta \mathrm{Up}$-gr $=0.46 * \mathrm{Ip}$ 0.005 , at $\mathrm{R}^{2}=0.9998$. In our measurements, in the absence of current in the pipeline segment under test, the potential is equal to Up-gr $=-0.33 \mathrm{~V}$. For the operating pipeline with a quiet geomagnetic situation, the measured potential Up-gr $=-0.26-0.33 \mathrm{~V}$. When the current passes through Pipeline there was a displacement of the potential in the positive direction, which causes increased corrosion in the pipeline.

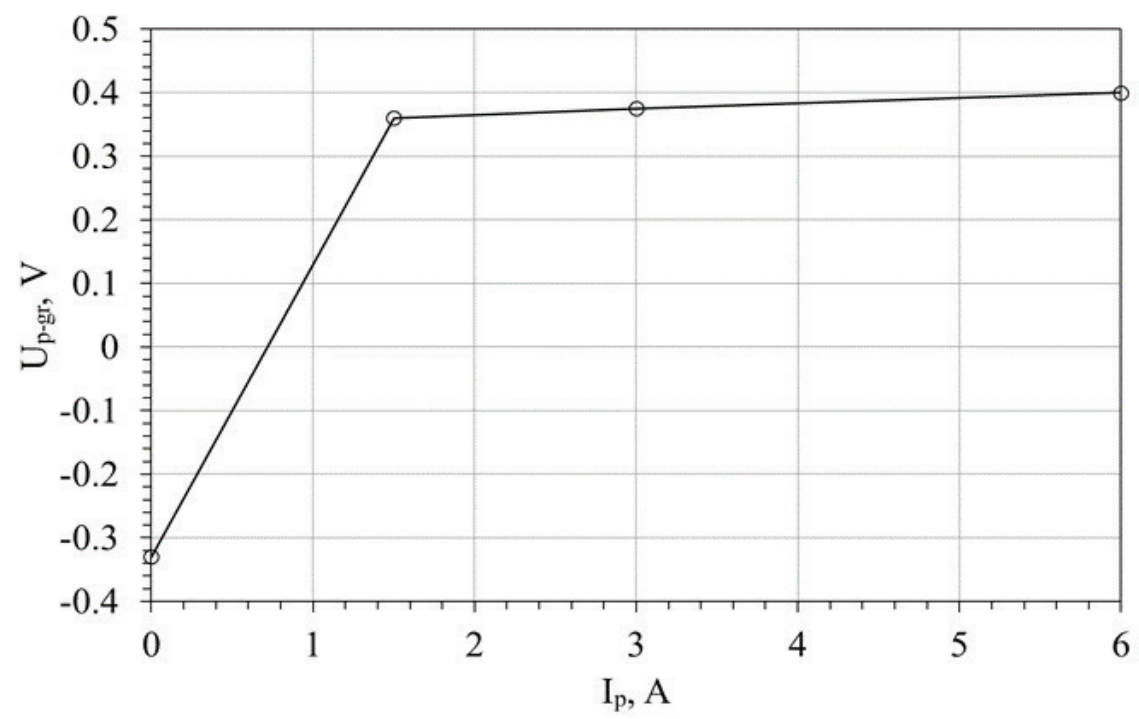

Figure 1. The experimental values of the potential difference $\Delta \mathrm{Up}$-gr "pipeline-ground" as a function of the magnitude of the constant electric field I $\mathrm{p}$ of the pipeline.

It was found in [5] that the potential "pipeline-ground" in the parts of the Punga-Vuktyl gas pipeline, where accidents often occurred, varied from -4.5 to $+2.5 \mathrm{~V}$. Test measurements of the pipeline-ground potential showed: if the current is zero, the potential will also be zero, and if the current rises to $5 \mathrm{~A}$, the potential will linearly increase to $1.6 \mathrm{~V}$. If the current goes in the opposite direction, the potential will change to $-0.5 \mathrm{~V}$. The 
potential difference ( $\Delta \mathrm{Up}$-gr) "pipeline-ground" depending on the current in the pipeline is expressed as $\Delta \mathrm{Up}-\mathrm{gr}=0,23 * \mathrm{Ip}$. The data correspond to our results, except for the saturation of the potential and the steepness of the dependence, which is determined by the state of the local soil. In our case, the pipeline surrounds the frozen ground.

It was shown in [6] that for geological auroral electrodes, as the causes of large horizontal components of magnetic field variations $(\mathrm{H})$ in auroral regions, the geographical northern component $(\mathrm{X})$ is clearly larger than the eastern $(\mathrm{Y})$, but $\mathrm{dX} / \mathrm{dt}$ and $\mathrm{dY} / \mathrm{dt}$ are almost equal. This is important when assessing the risks of occurrence of geomagnetically induced currents (GIT) in the main objects, since the horizontal geoelectric field can have large values in any direction, and not only parallel to the electrode. An important parameter for the investigation of the appearance of GIT is the probability of occurrence of large values of the time derivative of the horizontal component of the geomagnetic field $\mathrm{dB} / \mathrm{dt}$. The value of $\mathrm{dB} / \mathrm{dT}$ ) used to estimate GIT values has a high positive correlation with the number of sunspots (0.86) and aa-index (0.8998). 92.665\% of the obtained geomagnetic activity can be explained by the joint action of the indices of the number of sunspots and aa-index [7].

\section{Results and discussion}

Measurements of electric currents induced in the branches of the Tas-Yuryakh-Mirny oil pipeline with a diameter of $0.5 \mathrm{~m}$ during ground-based lightning discharges in the $1-10 \mathrm{~km}$ strip from the pipeline were measured. The same measurements were taken at the branch of a gas pipeline $110 \mathrm{~mm}$ in diameter and about $20 \mathrm{~km}$ long to the village of Tabaga from the main gas pipeline "Srednevilyuiskoye gas field - Mastakh-Berge-Yakutsk".

To observe the electromagnetic field oscillations emitted by induced currents in the pipeline, three horizontal magnetic loop antennas were used, located at different distances from the pipeline. To determine the location of the thunderstorm near the observation site, a one-point positioning system for lightning was installed at the IKFIA located at the polygon near Yakutsk and the Wolrd Wide Lightning Location Network (WWLLN) system [8], one of whose stations is located in Yakutsk [9]. It is obtained that the thunderstorm front moves with an average velocity of $44 \mathrm{~km} \mathrm{~h}^{-1}$ and has an average area of 5000-10000 $\mathrm{km}^{2}$ [10]. It follows that in the subpolar latitudes, lightning strikes of one thunderstorm occur within a radius of $10 \mathrm{~km}$ around the pipeline for 1-2 hours, even during a thunderstorm moving across the pipeline.

From the current flowing through the Tas-Yuryakh-Mirny pipeline during lightning discharges, the induced signal in the loop antenna located at a distance of $3.5 \mathrm{~m}$ from the pipe was 63 times greater than the current signal induced in the loop antenna located at a distance $150 \mathrm{~m}$. The distance to the lightning discharge was estimated from the time difference between the time of the lightning flash and the sound of thunder. A thunderstorm crossed the pipeline at a distance of 5-10 km from the observation point according to the data of the thunderstorm seekers.

Similar observations were made on a gas pipeline $30 \mathrm{~km}$ from Yakutsk when the thunderstorm was 3-10 km from the place of observation and crossed the branch of the pipeline to the village Tabaga. In these measurements, it was found that during a near- 
thunderstorm, the magnitude of the signal of the magnetic component of the electromagnetic field measured in the immediate vicinity of the pipeline was 190 times greater than the magnitude of the signal induced in the loop antenna located $400 \mathrm{~m}$ from the pipe. Calculated currents in the pipeline induced by ground-based lightning strike at a distance of 3-7 km from the observation site reached $10 \mathrm{~A}$.

The average annual number of lightning discharges in Yakutia in 2009-2016 is shown in Fig. 2. The density of discharges is corrected for the lightning discharge detection efficiency of the WWLLN system, which is $11-15 \%$ and about $30 \%$ for lightning discharges with a current of more than $100 \mathrm{kA}$ [11]. Density was calculated for the summer seasons (June 1 August 31) in 2009-2016, when thunderstorms are active in the territory under consideration.Measurements of the currents in the pipeline during geomagnetic storms were carried out on a branch to. Tabaga from the main gas pipeline "Srednevilyuiskoye gas field Mastah-Berge-Yakutsk" and branches between distribution stations No. 2 of Yakutsk and Pavlovsk, a pipeline $0.53 \mathrm{~m}$ in diameter from the gas distribution station No. 2 of Yakutsk comes under the ground to the village of Hatassy and further. A double gas pipeline is laid under the riverbed of the Lena River, on the opposite side of the river there is a gas distribution station in the village of Pavlovsk.

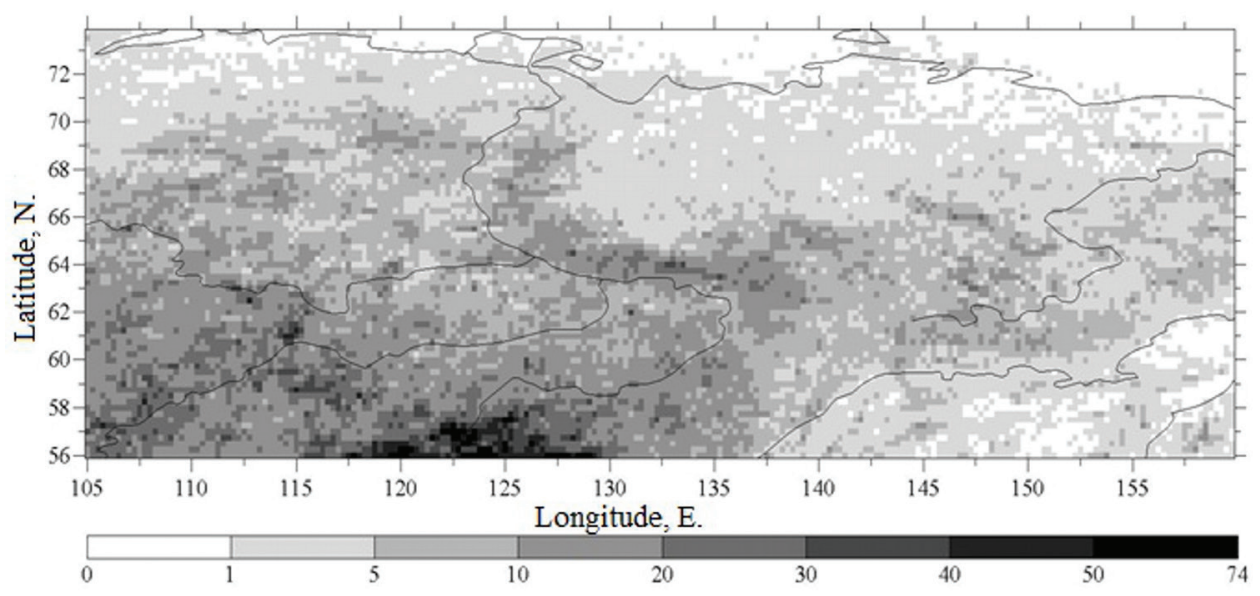

Figure 2. The average annual number of lightning discharges in Yakutia in 2009-2016.

To measure the induced currents flowing in the gas pipeline during geomagnetic disturbances, two magnetometers were used. One sensor was installed next to the pipeline ( $1 \mathrm{~m}$ distance), the second sensor (used for comparison) was installed at a distance of $600 \mathrm{~m}$ from the pipeline. The induced current was determined from the difference in the magnitudes of the magnetic disturbances measured at two sensors, proximal and far from the pipeline, taking into account the calibration. Test measurements to assess the sensitivity of the magnetic sensor were carried out using a current passing through the wire, which was located at a distance of $1 \mathrm{~m}$ from the sensor. During a calm geomagnetic situation, the magnetometers placed on the pipeline and at a distance of $600 \mathrm{~m}$ from the pipeline showed 
a similar noise pattern. This indicates that there are no induced quasi-permanent currents in the pipeline during small perturbations of the geomagnetic field.

Current measurements in the pipeline were made during three powerful geomagnetic storms. During a magnetic storm on January 21, 2005, the current in the pipeline 0.11 in diameter reached values of up to 3 A. During the storm on May 28, 2011, the current in the pipeline with a diameter of $0.53 \mathrm{~m}$ reached values of up to $0.5 \mathrm{~A}$. During the storm August 27,2013 , the current in the pipeline with a diameter of $0.53 \mathrm{~m}$ reached values of up to 0.3 A. An investigation of the measured current flowing through the pipeline during strong geomagnetic storms showed that the current reaches tens of amperes and lasts from several hours to several days.

The method of experimental investigation of the effect of geomagnetic disturbances on extended trunk objects can be reduced to the identification of time periods in which the value of the rate of increase of the magnetic field $(\mathrm{dB} / \mathrm{dt})$ above the threshold levels: $>5 \mathrm{nT}$ / min (active field), corrosion increases sharply in the absence of additional protection ; > $20 \mathrm{nT} / \mathrm{min}$ (storm), corrosion increases dramatically even with protection; > $30 \mathrm{nT} / \mathrm{min}$ (extreme storm) effects on energy systems [12].

It was shown in [13] that a closer functional connection is observed between the HIT and the magnitude of the magnetic field increase rate $(\mathrm{dB} / \mathrm{dt})$ than with the horizontal component of the geomagnetic field $\mathrm{H}$. A good correlation of the $\mathrm{dX} / \mathrm{dt}$ variations with the induced currents in the transmission line directed along the $\mathrm{X}$ is shown in [14].

It is proposed in [7] to use the published data of the International Real-time Magnetic Observatory Network as the magnitude of the magnetic field increase rate $(\mathrm{dB} / \mathrm{dt})$. Therefore, the study of variations in geomagnetic activity is carried out using the data of the rate of increase in the strength of the horizontal component $(\mathrm{dB} / \mathrm{dt})$ of the Yakutsk Observatory of the interregional data collection node for servicing the Russian-Ukrainian segment of the world network of the INTERMAGNET geomagnetic observatories. In the base INTERMAGNET data (Rate of Chanch dB / dt) of the Yakutsk Observatory (Yakutsk, YAK, 61.96 / 129.66) are presented with a minute resolution (http://www.intermagnet.org/data-donnee/dataplot-eng.php?type=xyz).

Consider the probability of exceeding a certain level $\mathrm{dB} / \mathrm{dt}$ by the example of a very strong magnetic storm August 05, 2011. From 17 to 20 hours, the disturbance level reached G4, and from 20 to 23 hours - G3. August 06 from 02 to 05 hours - G1. from 23 to 02 hours - G2, from 02 to 05 hours - G1. And then until 08:00 on August 07, 2011 the storm intensity gradually decreased. For the entire day August 05, 2011 time intervals with the rate of change of the magnetic field $>5 \mathrm{nT}$ were $7.15 \%,>20 \mathrm{nT} 1.18 \%,>30 \mathrm{nT} 0.42 \% \mathrm{~b}<$ $-5 \mathrm{nT} 6.6 \%,<-20 \mathrm{nT} 1.32 \%,<-30 \mathrm{nT} 0.56 \%$. The frequency of occurrence of a given level $\mathrm{dB} / \mathrm{dt}$ is determined by the expression $\mathrm{n}=444.84(\mathrm{~dB} / \mathrm{dt})-1.717$ where $\mathrm{R}^{2}=0.85$. Or the probability of exceeding the level can be expressed as: $\lg (\mathrm{P})=-0.057(\mathrm{~dB} / \mathrm{dt})-0.1946$, with $\mathrm{R}^{2}=0.99$.

When considering the dependence of the current in the pipeline on the rate of magnetic field variations, the example of a geomagnetic storm on May 28, 2011 found that the current in a pipeline, depending on the rate of magnetic field variations, $\mathrm{dB} / \mathrm{dt}$ [nT / $\mathrm{min}]$, can be expressed as (Fig. 3): $\mathrm{I}=0.024 *(\mathrm{~dB} / \mathrm{dt})+0.07$. That is, at $5 \mathrm{nT} / \mathrm{min}$, the GIT 
values appearing in the pipeline reach $1 \mathrm{~A}$. And this, in accordance with our measurements, leads to positive values of PPG, and hence to increased corrosion.

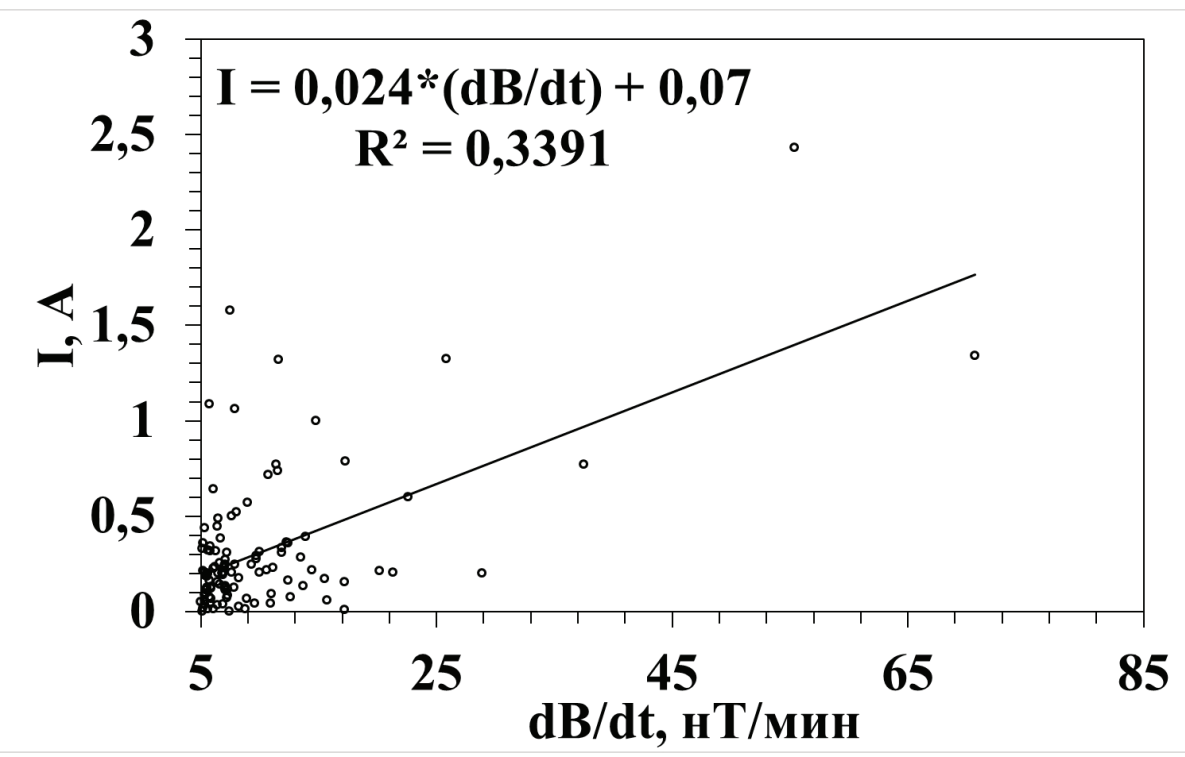

Figure 3. Current in the pipeline caused by variations of the magnetic field May 28, 2011.

At the magnetic station of Yakutsk in 2008-2013, the geomagnetic situation was characterized by the presence of isolated magnetic storms exceeding 305 times that of $\mathrm{dB} /$ $\mathrm{dt}>5 \mathrm{nT} / \mathrm{min}$, and $-\mathrm{dB} / \mathrm{dt}>20 \mathrm{nT} / \mathrm{min}-40$ times. Exceeding the levels of the rate of increase of the magnetic field intensity in 2014-2016 were observed: $>5 \mathrm{nT} / \mathrm{min} 118$ storms, > $10 \mathrm{nT} / \mathrm{min} 86$ storms, > $20 \mathrm{nT} / \mathrm{min} 41$ storms and > $30 \mathrm{nT} / \mathrm{min} 25$ storms. The maximum amount of magnetic disturbance is observed in spring and autumn.

Differential distribution of the occurrence of perturbations for storms 2014-2016. Is a power law and can be expressed by the formula $y=33,6 x^{-1,1}$, with the value of the determinant $\mathrm{R}^{2}=0,72$. The maximum observed disturbance is $163 \mathrm{nT} / \mathrm{min}$.

The characteristic individual differential distribution of the occurrence of the variation in the rate of change of the magnetic field $\mathrm{dB} / \mathrm{dt}, \mathrm{nT} /$ min under the magnetic storm $\mathrm{G} 4$ on June 22, 2015, is expressed by a power law. In the range of values from 1 to $10-20 \mathrm{nT} / \mathrm{min}$, the distribution has a steeper slope, expressed by the formula $\mathrm{y}=781 \mathrm{x}^{-1.7}$, at $\mathrm{R}^{2}=0.92$, compared to the interval from 10 to $100 \mathrm{nT} / \mathrm{min}$, where the distribution has more Sloping slope, expressed by the formula $y=76 \mathrm{x}^{-0.94}$, with $\mathrm{R}^{2}=0.73$.

The 14th magnetic storms for 2015 and January 2016 (the maximum geomagnetic activity in the 24th cycle of solar activity) were chosen to show the maximum values of the change in $\mathrm{dB} / \mathrm{dt}$ for 2014-2016. The value of the exponent of a single power law for events with a maximum variation in the rate of change of the magnetic field dB / dt from $6 \mathrm{nT} /$ $\mathrm{min}$ to $100 \mathrm{nT} / \mathrm{min}$ varies from -3.1 to -2.5 , and for events of the maximum range from 100 $\mathrm{nT} / \mathrm{min} \mathrm{Up}$ to $163 \mathrm{nT} / \mathrm{min}$ the value of the indicator varies from -2.2 to -1.2 . That is, as 
the value of $\mathrm{dB} / \mathrm{dt}$ increases, the value of the indicator decreases in absolute value, and therefore the distribution is being adjusted.

For magnetic storms, the probability of exceeding the threshold levels of the rate of increase of the magnetic disturbance was obtained at the maximum of the geomagnetic activity of the 24th solar cycle: $37 \%$ for $>5 \mathrm{nT} / \mathrm{min}, 8.3 \%$ for $>20 \mathrm{nT} / \mathrm{min}, 4.6 \%$ for $>30$ nT / Min.

The distribution of the directionality of the variations $\mathrm{dB} / \mathrm{dt}$ has a chaotic character without pronounced directivity, in contrast to the variation of the horizontal component of the magnetic field $\mathrm{H}$, which has a pronounced directionality.

In the 24th cycle, the maximum geomagnetic activity was observed in 2015 and in 2016 on the declining branch of solar activity. According to [15], the 24th solar cycle is the beginning of an epoch of "lowered" solar activity. It is assumed [16] that the epoch of "reduced" solar activity will last 5 solar cycles. It is expected that these solar cycles will be of low and medium activity. It is assumed in [15] that in this era solar flares can not significantly exceed the powerful flares already observed during instrumental observations. This makes it possible to assume that the conclusions drawn from our analysis of the magnitudes of the variations of magnetic activity from 2008 to 2016 can be applied to a future forty-year interval.

\section{Conclusions}

During strong geomagnetic storms and during a thunderstorm at a distance of $10 \mathrm{~km}$ around the pipeline, geomagnetic induced currents appear in it, reaching tens or even hundreds of amperes. As a result, the potential of the soil-pipeline increases and the corrosion of the pipeline is possibly increased.

The research is partially funded by RFBR No. 15-45-05005 r_vostok_a and a comprehensive research program in the Republic of Sakha (Yakutia).

\section{References}

[1] S. V. Avakyan, N.A. Voronin, Issledovanie Zemli iz kosmosa, 3, 14-29 (2011) (in Russian)

[2] J. M. Torta, S. Marsal, M. Quintana, Earth Planets and Space, 66:1, 87 (2014)

[3] D. H. Boteler, Advances in Space Research, 26:1, 15-20 (2000)

[4] Yu. I. Garber, Stroitel'stvo truboprovodov, 9, 28-30 (1992) (in Russian)

[5] A.V. Furkin, M.V. Tret'yakova, R.V. Aginey, Trudy Komi nauchnogo tsentra Ural'skogo otdeleniya Rossiyskoy akademii nauk, 1:17, 80-83 (2014) (in Russian) 
[6] A. Viljanen, Geophysical Research Letters, 24:6, 631-634 (1997)

[7] E.O. Falayi, A.B. Rabiu, Frontiers in Science, 2:1, 1-5 (2012)

[8] R. L. Dowden, J. B. Brundell, C. J. Rodger, J. Atmos. Solar-Terr. Phys., 64:7, 817-879 (2002)

[9] L. D. Tarabukina, V. I. Kozlov, R. R. Karimov, V. A. Mullayarov, Proc. SPIE 9680, 96805S (2015)

[10] V. I. Kozlov, V. A. Mullayarov, A. E. Vasilyev, Russian Meteorology and Hydrology, 3, 27-31 (2003)

[11] S. F. Abarca, K. L. Corbosiero, T. J. Galarneau Jr., J. Geophys. Res. 115, D18206 (2010)

[12] J. Koen, C.T. Gaunt, Geomagnetically induced currents at mid-latitudes. URSI, Maastricht, (2002)

[13] A. Viljanen, Geophysical research letters, 24:6, 631-634 (1997)

[14] V. A. Pilipenko et al., Trudy Kol'skogo nauchnogo tsentra RAN, 4-2, 38 (2016)

[15] V. N. Ishkov, Vestnik ONZ RAN, 8, NZ5001 (2016) (in Russian)

[16] V. N. Ishkov, Sb. «Solnechnaya i solnechno-zemnaya fizika-2013», 111-114 (2013) 